\title{
Learning of colonial odor in the ant Cataglyphis niger (Hymenoptera; Formicidae)
}

\author{
ELISE Nowbahari \\ UMR CNRS 7153, Université Paris Nord, Villetaneuse, France
}

\begin{abstract}
Ants learn the odors of members of their colony early in postnatal life, but their ability to learn to recognize noncolony conspecifics and heterospecifics has never been explored. We used a habituation-discrimination paradigm to assess individual recognition in adult Formicine ants, Cataglyphis niger. Pairs of workers from different colonies were placed together for repeated trials, and their ability to discriminate the ant that they encountered from another familiar or unfamiliar ant was observed. Some ants were isolated between encounters, and others were returned to their home colonies. Our results suggest for the first time in ants that $C$. niger adults learn about individual ants that they have encountered and recognize them in subsequent encounters. Ants are less aggressive toward non-nestmates after they are familiar with one another, but they are aggressive again when they encounter an unfamiliar individual. Learning about non-nestmates does not interfere with an ant's memory of members from its own colony.
\end{abstract}

In social insects, nestmate recognition plays an essential role in social organization. Given the importance of nestmate discrimination in social behavior, it is not surprising that many investigators have attempted to determine the nature of the signals that insects use for such recognition (called labels or cues), their sites of production, and the discrimination ability of individuals throughout ontogenesis (see Breed, 1998, for a review). These studies have demonstrated that nestmate recognition is based on chemical cues - mainly cuticular hydrocarbons - which are species and colony specific in both composition and concentration (see, e.g., Breed \& Bennett, 1987; Howard, 1993; Lahav, Soroker, Hefetz, \& Vander Meer, 1999; Lenoir, Fresneau, Errard, \& Hefetz, 1999; Nowbahari et al., 1990; Soroker, Vienne, Hefetz, \& Nowbahari, 1994). Individuals within a colony often differ from heterospecific individuals as well as conspecific non-nestmates in both genetic and environmental cues. Recognition cues are learned by workers and serve as a template to determine the colonial membership of each individual encountered (Breed \& Bennett, 1987; Breed \& Julian, 1992; Greenberg, 1988; Pfenning, Gamboa, Reeve, Shellman-Reeve, \& Ferguson, 1983; Stuart, 1987).

In contrast to the important advances in the determination of the nature of the signals involved in nestmate recognition, less experimental progress has been achieved in the attempt to understand the mechanisms, or decision rules, underlying the behavior of individuals during encounters. The mechanisms underlying amicable or aggressive behaviors performed by one individual facing another could be based on the comparison of the perceived signal with the individual's own signal or template, as has been revealed mostly by studies focusing on territorial behavior. Notable among invertebrate studies are those that investigate a phenomenon known as "dear-enemy" which has been studied largely in vertebrates (see, e.g., Temeles, 1994). In eusocial Hymenoptera and particularly in ants, the "dear-enemy" phenomenon refers to a pattern of aggression where neighbors are discriminated from strangers and are the object of less aggression (Heinze, Foitzik, Hippert, \& Hölldobler, 1996; Knaden \& Wehner, 2003; Pfenning et al., 1983). The mechanisms by which neighbors are discriminated from strangers and the function of neighbor-stranger discrimination has not been clearly determined, but it has been suggested that individual recognition based on odor learning is involved (Obin \& Vander Meer, 1988).

Another largely unsolved problem regarding nestmate recognition is the impact of memory on the integration of perceived signals. Adoption experiments point out the existence of a sensitive learning period during which the sensory imaging of perceived signals is formed. In ants, as in other social insects, during this sensitive period the sensory imaging of a template of colonial odor is learned, and it appears to be an imprinting-like phenomenon starting in early life at the larval stage (Carlin, Halpern, Hölldobler, \& Schwartz, 1987; Isingrini, Lenoir, \& Jaisson, 1985) or during the first days of adult life (Fénéron \& Jaisson, 1995; Isingrini et al., 1985; Morel, 1982), with long-term memory effects lasting 1 year (Errard, 1994). In Camponotus vagus ants, Morel showed that emerging within the colony is important for colonial odor recognition. Le Moli and Mori (1985) also found that early experience in Formica cunicularia strongly influenced intra- and interspecific relationships. In Cataglyphis cursor, the sensitive learning period corresponds to the 4 days following emergence (Nowbahari \& Lenoir,

E. Nowbahari, elise.nowbahari@leec.univ-paris13.fr 
1989). Early experience may thus induce a preference for a particular social environment and explain observed natural associations between different species of ants (Errard, 1994). But learning and recognition memory of any encountered ants has to be plastic rather than fixed, and thus not limited to the early postnatal period. Experimental evidence, obtained, for example, in the study of hydrocarbons of individuals isolated from their colonies, has demonstrated that their chemical labels deviate from that of the mother colony (Boulay \& Lenoir, 2001; Lenoir, Cuisset, \& Hefetz, 2001). Therefore, an efficient learning system has to be flexible and must continue throughout the entire lifetime of the ant.

This article reports non-nestmate odor learning during encounters between mature adult ants. It describes individual odor discrimination and the capacity of Cataglyphis niger adult ants to modulate their reactions toward non-nestmates. Its particular objective was to investigate the following questions: Do the adult workers of $C$. niger change their reactions toward a foreign individual that they encounter repeatedly? In other words, do they recognize familiar non-nestmates? After they learn to recognize the non-nestmate during successive encounters, do they change their behavior toward members of their colony?

\section{EXPERIMENT 1 Conspecific Encounters}

Two experiments were conducted. Experiment 1 used habituation/discrimination trials in which repeated encounters between 2 individuals resulted in a decrease of aggressiveness (habituation) followed by an increase in responsiveness (discrimination) when a novel individual was encountered. In this experiment, encounters between 2 ants (dyadic encounters) from two distant colonies of $C$. niger were performed, followed by a trial with a novel ant to confirm the discrimination between 2 ants.

\section{Method}

Ants and rearing conditions. Nine polygynous (including more then one reproductive female) colonies of $C$. niger were collected from two areas to the north (Netanya) and south (Rishon LeZion) of Tel Aviv. These sites extend over a distance of some $15 \mathrm{~km}$ and are more than $50 \mathrm{~km}$ (31.07 miles) apart. In a previous study of intercolonial recognition in C. niger, we observed a high level of aggression between individuals from different colonies from these sites (Nowbahari, Fénéron, \& Malherbe, 1999).

In the laboratory, colonies were maintained under homogeneous conditions (a temperature of $25^{\circ}-28^{\circ} \mathrm{C}$ ) to reduce as much as possible the influence of temperature and nutrition on behavior. They were reared in similar artificial nests consisting of a round plastic box ( $15 \mathrm{~cm}$ in diameter) colored in black and connected to a foraging arena $(28 \times 27.5 \times 8.5 \mathrm{~cm})$. They were fed on mealworm larvae and a honey/apple mixture twice a week.

Behavioral observations and data analysis. We used a classical habituation/discrimination paradigm (see Manning \& Dawkins, 1998; Todrank \& Heth, 2003). The behavioral trials consisted of dyadic encounters between ants from two C. niger colonies (Figure 1). One ant was from a colony collected in Netanya (Colony A), and the other was from a colony collected in Rishon le Zion (Colony B).

The habituation portion consisted of 10 repeated encounters. To stage an encounter, with cleaned forceps we transferred 2 workers from the origin colony into a neutral arena: a round plastic box $9 \mathrm{~cm}$ in diameter, the bottom of which was covered with filter paper changed for each encounter and the walls of which were coated with fluon to prevent climbing. Where possible, the tested workers were sampled from among the forager workers in the foraging arena of the colony or within the nest. The ants were marked on the thorax

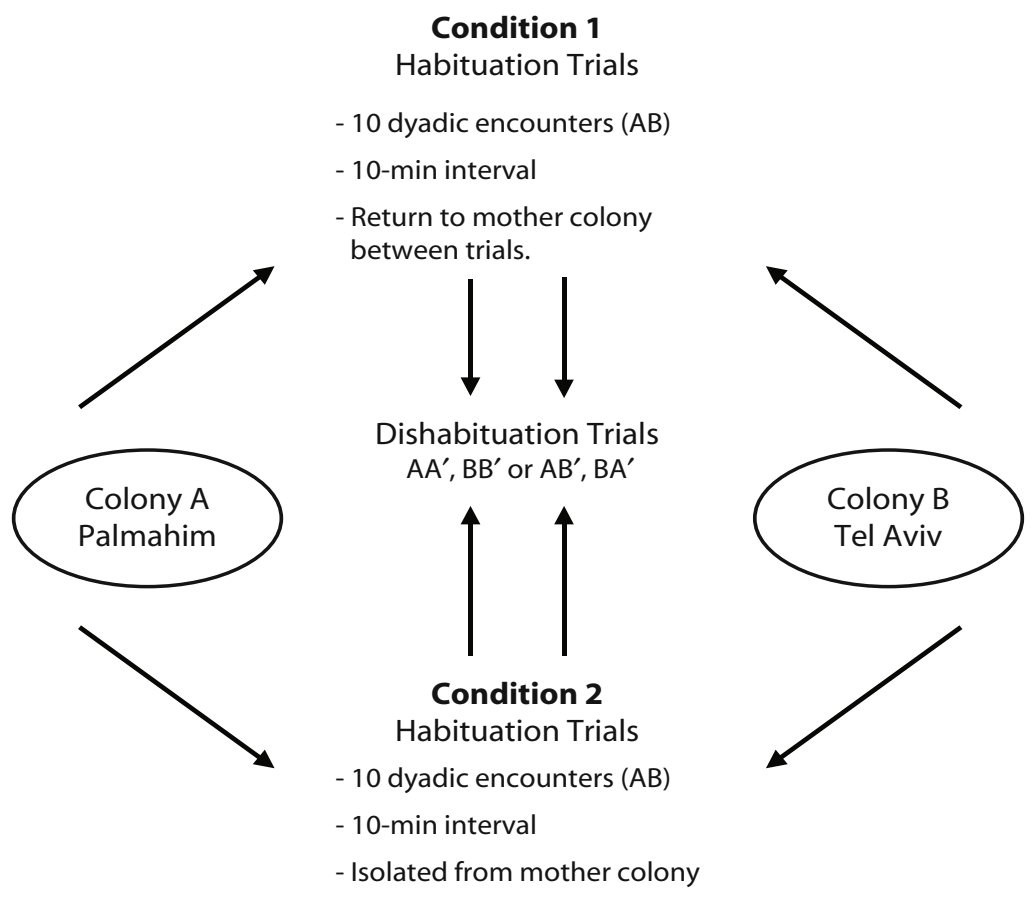

Figure 1. Method used in Experiment 1: Conspecific tests. $A^{\prime}$ and $B^{\prime}$, nestmates for $A$ and $B$ encountered ants. Palmahim and Tel Aviv were the two different sites where ants were obtained. 
with a distinct spot of odorless indelible paint (Uni Paint Marker PX 20, Mitsubishi Pencil Co.) according to their colonial origin. Before each encounter, both workers were placed for $2 \mathrm{~min}$ in separate glass cylinders inside the arena to keep them calm. The test began with careful removal of the cylinders. All behaviors performed by each worker were recorded, by direct visual scoring, according to the scan sampling method, every $5 \mathrm{sec}$ for $3 \mathrm{~min}$. The habituation dyadic encounter trials were performed with the same individuals 10 times, with an intertrial interval of $10 \mathrm{~min}$. At the end of each series of 10 encounters, we performed a discrimination trial, in which the subject ants were confronted with novel ants. During this trial, each ant from Colony A or B was confronted with a nestmate or with an unfamiliar non-nestmate issued from the same colony as that of the encounter ants. This permitted us to verify whether or not the ant (1) distinguished between non-nestmate odors and its colonial odor, which was probably learned during the early sensitive period, and (2) differentiated a familiar non-nestmate from an unfamiliar one (i.e., differentiated individually 2 sisters that had very similar odors).

In these trials, we investigated the modification of the ant's behavior over successive encounters with previously unfamiliar ants. The tests were conducted in two different conditions.

Condition 1: Successive trials with isolated workers. During the 10-min interval between trials, the opponent workers remained isolated from their colony and were kept in two separate cylinder boxes. A total of 27 series of tests were performed, so that 54 workers were tested.

Condition 2: Successive trials with nonisolated workers. During the interval between trials, the opponent workers were replaced into their respective colonies. A total of 33 series of tests were performed, so that 66 workers were tested. These tests were performed to determine whether access to the worker's colonial odor and eventually the comparison of that odor with the encountered non-nestmate odor would modify the worker's behaviors during the tests. We hypothesized that the ants that returned to their mother colony between trials would be less stressed or might refresh their colony odor memory, as was observed previously in Camponotus fellah (Boulay, KatzavGozansky, Hefetz, \& Lenoir, 2004)

For each trial, all behaviors displayed by each worker were recorded every $5 \mathrm{sec}$ for $3 \mathrm{~min}$ (Table 1). We obtained a total of 36 behavioral records for each ant. Only agonistic behaviors and self-grooming that changed during the successive trials were analyzed here. These included aggressive behaviors (i.e., biting, flexing the gaster forward, and spraying formic acid), threatening behaviors (i.e., wide opening of mandibles), and nonaggressive behaviors (i.e., self-grooming). The frequency with which these behaviors were performed during each trial ( $3 \mathrm{~min}$ ) was calculated for each individual.

Comparisons between the successive trials in both conditions were made using Friedman tests. Comparisons between the two conditions were made using a permutation test for two independent samples.

To study changes in behaviors across the 10 trials, we used Helmert contrasts to compare the mean of the 1 st trial with the means of the subsequent trials. If there were significant differences, we compared the mean of Trial 2 with the mean of the remaining trials, and so forth. Contrasts were no longer significant when asymptote was reached.

We also used permutation tests for two related samples to compare the discrimination trial (Trial 11) with Trial 10. The statistics were considered significant at $p<.05$. All statistics were performed with StatXact 7 software.

\section{Results}

As a whole, whether isolated or not, $C$. niger ants confronted with a heterocolonial (conspecific) non-nestmate modified their behaviors during the 10 successive dyadic encounters. Aggressive behaviors, usually considered an accurate measure of nestmate recognition, changed the most (Figure 2). In general, the tested ants significantly changed their level of aggression over the trials (Friedman test, $p=.005)$. We observed a significant change of aggressive behaviors during the 10 trials, for both nonisolated ants $(p<.001)$ and isolated ants $(p=.03)$. But, the mean level of aggression over the 10 trials was higher in isolated ants (Condition 1) than in nonisolated ants (Condition 2) (permutation test for two independent samples, $p=.03$ ).

For nonisolated ants (Condition 1), aggressive behaviors were more frequent during the first encounter in comparison with the mean of the subsequent encounters (Helmert contrasts, permutation test for related samples, $p<.001)$. They were also more frequent during the second encounter in comparison with the mean of the subsequent encounters $(p<.01)$. But the following Helmert contrasts were not significant. So the asymptote level was reached in the third trial. For isolated ants (Condition 2), Helmert contrasts were not significant for aggressive behaviors.

Similarly to aggressive behaviors, threatening behaviors changed over all the successive trials $(p<.001$, Figure $3 \mathrm{~A})$. We observed a significant change of threatening behaviors during the 10 trials for nonisolated ants $(p<$ $.001)$, but no significant change for isolated ants $(p=$ .34). There was no significant difference between isolated and nonisolated ants for the mean level of threatening behaviors over the 10 trials $(p=.37)$.

For nonisolated ants, threatening behaviors were more frequent during the first encounter in comparison with the mean of the subsequent encounters (Helmert contrasts, permutation test for two related samples, $p=.001)$. They

Table 1

Description of All Behaviors Observed During Trials

\begin{tabular}{|c|c|}
\hline Behavior & Description \\
\hline \multicolumn{2}{|l|}{ Nonaggressive } \\
\hline Exploration movement & $\begin{array}{l}\text { The ant moves in test area. } \\
\text { No interaction with the other ant. }\end{array}$ \\
\hline Inactivity & $\begin{array}{l}\text { The ant is motionless. } \\
\text { No interaction with the other ant. }\end{array}$ \\
\hline Antennal contacts & Inspection with antennation contact of different body parts of the encountered ant. \\
\hline Grooming & $\begin{array}{l}\text { Self-grooming of different parts of body, such as the antenna, legs and mandibles. } \\
\text { No interaction with the other ant. }\end{array}$ \\
\hline Trophallactic exchanges & Oral food exchange. \\
\hline Aggressive & $\begin{array}{l}\text { Biting (seizing the opposite ant with the mandibles), threatening } \\
\text { (opening of mandibles), spraying of formic acid. }\end{array}$ \\
\hline Other & Submission (motionless in nymphal position), running away. \\
\hline
\end{tabular}




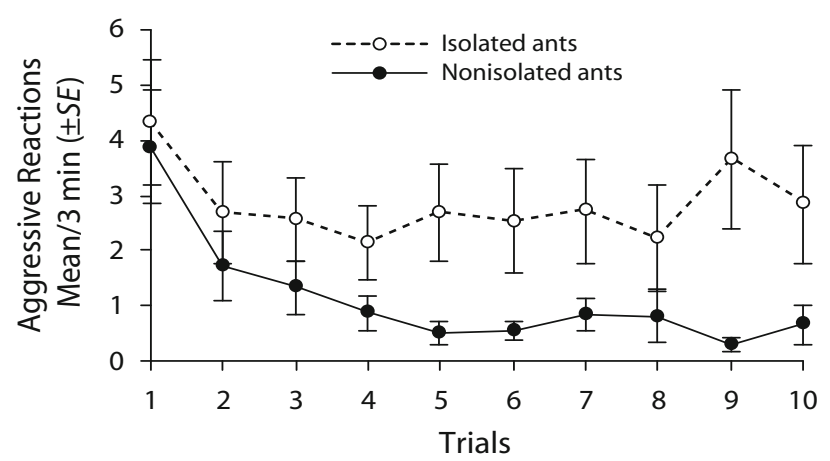

Figure 2. Mean $( \pm S E)$ aggressive reactions $/ 3 \mathrm{~min}$ of conspecific ants' encounters during 10 successive trials in two conditions: isolated and nonisolated condition. Aggressive reactions were recorded by sampling every 5 sec.

were also more frequent during the second encounter in comparison with the mean of the subsequent encounters $(p=.03)$ and during the third in comparison with the mean of the remaining encounters $(p=.05)$. But the subsequent Helmert contrasts were not significant. The asymptote level was reached in the fourth trial. For isolated ants, Helmert contrasts were not significant for threatening behaviors. Threatening behavior usually preceded overt aggression (i.e., biting and venom spraying), but sometimes it occurred alone or was followed by either intensive antennation or self-grooming.

Self-grooming changed significantly during the successive trials $(p<.0005)$. We observed a significant change of this behavior during the 10 trials for both nonisolated ants $(p<.0001)$ and isolated ants $(p<.0001)$. The mean level of self-grooming was significantly higher for the isolated than for the nonisolated ants ( $p=.02$ ) (Figure 3B). For nonisolated ants, it was more frequent during the first encounter in comparison with the mean of the subsequent encounters $(p=.003)$. They were also more frequent during the second encounter in comparison with the mean of the following encounters $(p=.03)$. But the subsequent Helmert contrasts were not significant. The asymptote level was reached in the third trial.

For isolated ants, we observed asymptote level in the fourth trial. The mean level of self-grooming was higher during the first encounter in comparison with the mean of the subsequent encounters $(p=.02)$, during the second encounter in comparison with the mean of the subsequent encounters $(p=.001)$, and during the third in comparison with the mean of remaining encounters $(p=.009)$. The subsequent Helmert contrasts were not significant.

Following the habituation trials, we performed a discrimination trial, in which the subject ants were confronted with novel ants from the same colony as that of the previously encountered ant. During this trial, each ant from Colony A or B was confronted with a nestmate or an unfamiliar non-nestmate.

The results of the discrimination trials (Trial 11) showed that the frequencies of displayed aggressive behaviors differed when ants encountered their nestmates and unfamiliar non-nestmates: There was virtually no aggressiveness toward nestmates (Figure 4).
The nonisolated and isolated ants confronted with a heterocolonial unfamiliar non-nestmate increased their aggressive behaviors during the discrimination trial (two related-samples permutation tests: nonisolated ants, $n=$ $35, p<.001$; isolated ants, $n=22, p=.05$ ). In addition, the mean level of aggression in the discrimination trial was higher for isolated ants than for nonisolated ants ( $p=$ .05 ). These ants, when they encountered a homocolonial ant, actually decreased their aggressive behaviors significantly (nonisolated ants, $n=31, p<.03$; isolated ants, $n=32, p=.04)$. There were no differences between isolated ants and nonisolated ants in these trials $(p=.97)$

\section{Discussion}

Our results from Experiment 1 show that $C$. niger adult ants are able to discriminate between conspecific nonnestmates. The hostility toward ants of alien colonies during the first encounter and the lack of aggression when they encounter their colony members outside the colony is well-known evidence of colony recognition. The decrease in aggressive and threatening behaviors, exhibited by both socially isolated (Condition 1) and socially nonisolated (Condition 2) ants, demonstrates that ants habituate to individual foreign odors over successive encounters. A recent study in ants has reported a peripheral recognition mechanism in detecting colony-specific chemical signals by chemosensory sensillum (Ozaki et al., 2005).

However, isolated and nonisolated workers did not behave similarly with regard to non-nestmate recognition. We
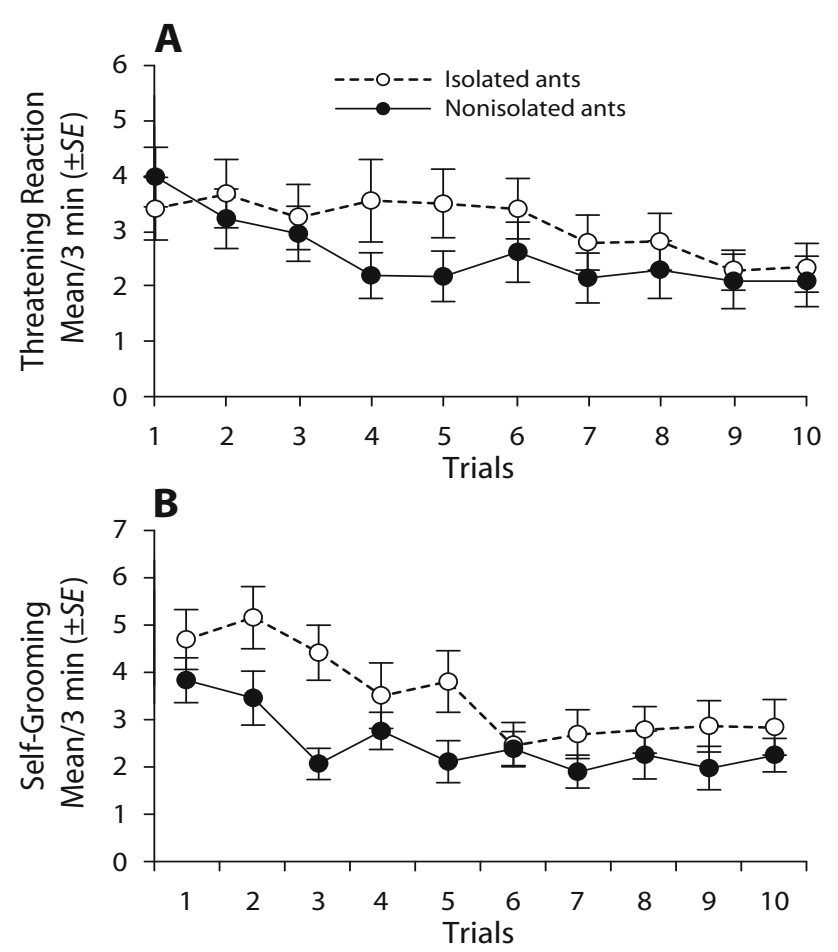

Figure 3. Mean $( \pm S E)$ threatening (A) and self-grooming (B) reactions/3 min of conspecific ants' encounters during 10 successive trials in two conditions: isolated and nonisolated condition. Threatening and self-grooming reactions were recorded by sampling every 5 sec. 
observed a more rapid decline in the level of aggression (i.e., habituation) in ants that were returned to their mother colony and less of a decline in the level of aggression when the ants were maintained in isolation from their colony.

We noted that only some of the ants were aggressive. But all of the aggressive ants remained aggressive throughout the trials even though the frequency of aggression decreased. Similarly, workers that did not display any aggression during the first encounter showed consistent behavior and remained nonaggressive throughout the trials. This result suggests that in $C$. niger there is a division of labor in defensive behavior, which is usually performed by foragers. Nowbahari et al. (1999) demonstrated that in $C$. niger, only large workers that were also the foragers evolved alternative fighting strategies. It seems that, in social insects, foragers who generally have the defensive role possess higher nestmate recognition ability (Breed, Smith, \& Torres, 1992).

The results from the discrimination trials indicate clearly that the C. niger ants after successive encounters with a non-nestmate recognize their nestmate and can discriminate the odor of an unfamiliar non-nestmate, which theoretically has a very similar odor to that of the previously encountered ant.

\section{EXPERIMENT 2 Heterospecific Encounters}

To determine whether ants discriminate between different heterospecific individuals, Experiment 2 was conducted with successive dyadic encounters between two different species: C. niger and Cataglyphis cursor. This experiment permitted us to determine how ants react to a variety of non-nestmates in consecutive encounters.

\section{Method}

Ants and rearing conditions. In Experiment 2 we used the same polygynous colonies as in Experiment 1, which were collected in Israel, as well as three monogynous colonies (each including one reproductive female) of C. cursor, collected near Perpignan (in southern France). Preliminary observations indicated that these colonies did not show intercolonial aggression (see Nowbahari et al., 1990).

The colonies were maintained in artificial nests and conditions similar to those in Experiment 1.

Behavioral observations and data analysis. This experiment was conducted in the same way as was Experiment 1, to determine how an ant would react in heterospecific dyadic encounters with 1 ant from a $C$. niger colony collected in Israel and a 2 nd from a $C$. cursor colony collected in France. Preliminary observations indicated that ants confronting heterospecific individuals exhibit overt aggression, perhaps because of the substantial differences in the chemical signature between these ants (for the chemical analysis of $C$. cursor, see Nowbahari et al., 1990, and for C. niger, see Soroker et al., 1994). Here nearly all tested ants exhibited aggressive behaviors. A total of 17 series of tests were performed, but because of high aggression levels and the mortality of 1 of the tested ants during the trials, only 7 series could be analyzed, corresponding to 7 tested workers.

We also assessed the reactions of an ant toward different heterospecific ants; that is, the partners were changed in successive trials. Here we also observed high aggressiveness, and we analyzed the reactions of $10 C$. niger ants encountering successively 7 different C. cursor ants. In Experiment 2, as in Experiment 1, all behaviors displayed during the tests were recorded (Table 1), but only the results of aggressive behaviors are presented and analyzed here.

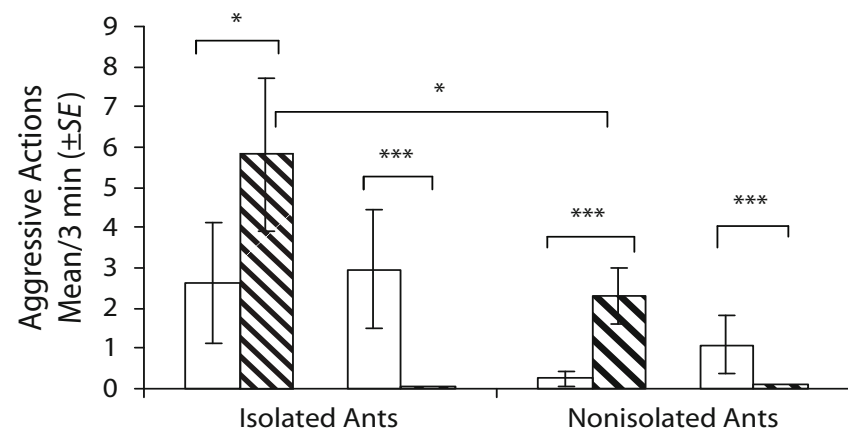

Figure 4. Mean $( \pm S E)$ aggressive reactions/3 $\mathrm{min}$ of the habituated ants when they encountered a known conspecific nonnestmate in the 10th trial (unfilled bars) and then an unknown non-nestmate ant in the 11th trial or dishabituation trial (hatched bars) or a nestmate in test trial (filled bars), in two conditions: isolated and nonisolated conditions. Aggressive reactions were recorded by sampling every 5 sec. $\quad * p<.05 .{ }^{* * *} p<.001$.

Comparisons between the successive trials in both conditions were made using Friedman tests. Comparisons between two conditions were made using a permutation test for two independent samples. To study changes in behaviors across the 10 trials, we used Helmert contrasts.

\section{Results}

When C. niger ants encountered a heterospecific ant (C. cursor), they exhibited overt aggression. These aggressive reactions were followed by a significant reduction over 10 successive trials with the same individual $(p<.001)$, followed by an increase in aggression during the discrimination trials ( $p=.03 ; n=7$; Figure 5$)$. We observed a stronger aggressive reaction in the first trial in heterospecific encounters (average of aggressive behavior in the first encounter $=18.8 \pm 2.2$ ) in comparison with the dyadic conspecific encounters presented in Figure 2 (average of aggressive behavior in first encounter $=4.07 \pm 1.03$ ).

As in homospecific encounters (Experiment 1), in heterospecific encounters aggressive behaviors were more frequent during the first encounter in comparison with the mean of the subsequent encounters $(p<.01)$. They were also more frequent during the second encounter in comparison with the mean of the following encounters $(p<.03)$. But the following Helmert contrasts were not significant.

When $C$. niger encountered different heterospecific individual ants (C. cursor) in successive trials, the aggressive level did not change significantly, and there was no reduction in their aggressive behaviors $(p=.5)$ (see Figure 5).

\section{Discussion}

These results confirm the results of Experiment 1. But in Experiment 2, with heterospecific encounters, we observed higher aggressiveness in the first trial and a rapid reduction of this reaction during the 10 successive encounters. The asymptote level was reached in the second encounter in the third trial for nonisolated ants, and it was not established for isolated ants (Experiment 1). This difference could have been due to the greater odor similarity between the ants of the conspecific as opposed to the heterospecific 
colonies. The process of comparing the learned template of the colonial odor with the individual foreign odors could be the reason for the stronger modification of the level of aggression observed in heterospecific encounter trials.

The results of dyadic encounters of an ant facing two different heterospecific partners indicate that the ants did not react identically when faced with the different individuals or the same individuals in successive trials. We did not observe a reduction of aggressive behaviors. This result confirms that the reduction in aggressiveness observed across encounters with the same individual was a habituation process and not the result of tiredness.

\section{GENERAL DISCUSSION}

The results of our experiments showed that $C$. niger adult ants can learn individual new odors of conspecific or heterospecific ants. Individual learning in ants is known only in the queen recognition of Pachycondyla villosa, a primitive Ponerine ant that forms very small societies. It is now well known that in these ants the queen odor is a fertility signal very different from the odor of workers and is therefore probably easy to discriminate (D'Ettorre \& Heinze, 2005). Our data are the first obtained for large societies in which individual discrimination has been considered improbable. They confirm the large olfactory learning possibilities of ants, as demonstrated in Camponotus workers (Dupuy, Sandoz, Giufra, \& Josens, 2006).

Although more investigations will be necessary for researchers who wish to understand the mechanisms of recognition systems in ants, it seems that ants modulate their defensive actions according to environmental context (Carlin \& Johnston, 1984; Temeles, 1994). The study of nestmate recognition and spatial variation in aggressive behavior in Camponotus chilensis has shown that C. chilensis individuals are able to discriminate nestmates from intruders, with no aggression toward nest companions but with aggressiveness toward heterocolonial conspecifics that decreases significantly with distance (Velásquez, Gómez, González, \& Vásquez, 2006).
In ants, the modification of reactions through learning is observed in field and experimental situations of territorial defense as an increase in aggressive behaviors, a phenomenon known as enemy specification (Carlin \& Johnston, 1984; Obin \& Vander Meer, 1988; Wilson, 1975). Enemy specification presents evidence for strong discrimination between different types of intruders in the intensity of the stimulus required for activation of a response. The intensity of the stimulus can be increased by repeated introductions of alien ants. The decrease in the level of aggression through habituation, as in C. niger, and its increase through sensitization, as in other ant species such as Pheidole dentata (Carlin \& Johnston, 1984; Velásquez et al., 2006; Wilson, 1975), are probably some of the simple types of learning in invertebrates as described by Abramson (1997). In our experiments, we considered the decrease in the frequencies of aggression as non-nestmate odor learning and as recognition of a previously encountered individual. The differences in aggressiveness during the habituation and discrimination trials in two conditions, as well as the observed differences when $C$. niger encountered a conspecific in comparison with a heterospecific ant, confirm these results of context dependence of recognition processes. This result could correspond to the "dear-enemy" phenomenon, which may be mediated by simple recognition learning as has been suggested by Langen, Tripet, and Nonacs (2000) in Pheidole ants and reported by Heinze et al. (1996) within and between species of Leptothorax. In C. niger, workers meeting in a neutral arena probably reduce their motivation to be aggressive toward non-nestmates over time. In addition, our analysis suggests the efficacy of future field studies in natural territories in order to assess whether or not the intensity of a worker's responses is an adaptive consequence of the economics of territorial defense. In the field, aggressive interactions with less threatening neighbors can represent wasted energy, which would be better utilized in the defense of the territory against strangers. The variation in aggression between spatially distant colonies also suggests that additional genetic or environmental factors are involved in differential discriminative responses (Heinze et al., 1996).

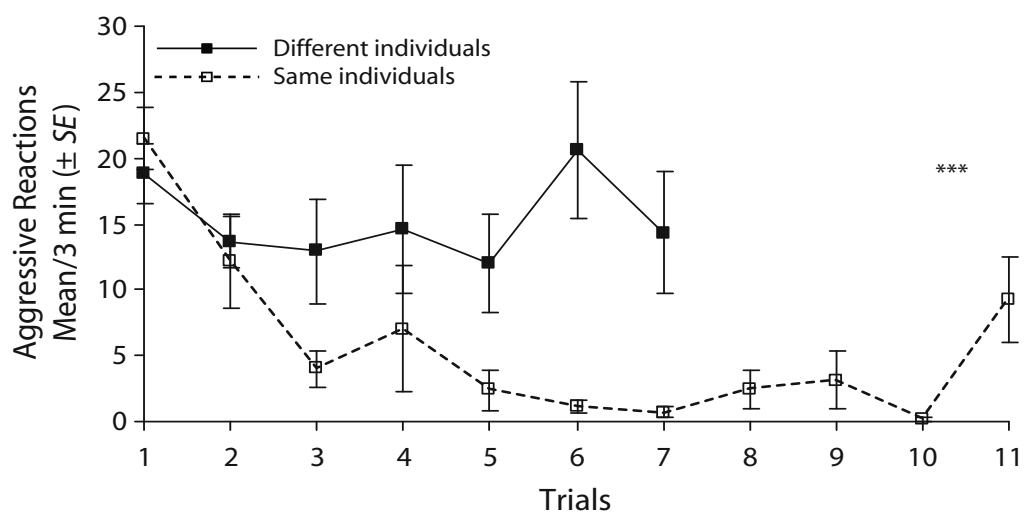

Figure 5. Mean $( \pm S E)$ aggressive reactions $/ 3 \mathrm{~min}$ of ants in encounters with the same heterospecific ant during 10 successive trials and then with a native heterospecific in dishabituation trial (Trial 11), or when encountering different individuals during 7 trials. Aggressive reactions were recorded by sampling every 5 sec. ${ }^{* * * *} p<.001$. 
C. niger adult ants seem to learn new odors. Although historically habituation was dismissed as a functionally insignificant form of behavior, most contemporary scientists view habituation as a form of adaptive modification of behavior, as in learning (Wyers, Peeke, \& Herz, 1973). This process seems to be more accurate when $C$. niger workers have the opportunity to compare the opponent's individual odor with their own reference (i.e., their colonial odor, Experiment 1). Indeed, we observed a more rapid decrease in the level of aggression (i.e., habituation) in ants that were returned to their colony. Ants isolated from their colony appear to use their long-term memory capacity to distinguish their opponents, most likely by comparing the opponents' odors with the memorized colonial odor learned during the sensitive period. This behavioral difference between isolated and nonisolated ants seems to indicate that short-term memory is involved in nonnestmate odor learning in $C$. niger adult ants as has previously been observed in bees (Erber, Masuhr, \& Menzel, 1980). C. niger ants act as if they do not exclusively use their own odor as a reference for nestmate recognition. Isolated ants seem to learn the odor of non-nestmates as well as that of the nonisolated ants. But the ants that have the possibility of returning to their nest seemed to have better learning of non-nestmate odors. They rapidly decreased their agonistic level during the habituation trials and reacted significantly more aggressively with a novel non-nestmate in the discrimination test. As Lenoir et al. (2001) reported, the isolated condition could induce some changes in cuticular hydrocarbon profiles and cause a different reaction toward non-nestmates. These authors observed overt aggression toward isolated ants when these were reintroduced into their mother colonies.

Therefore, the ability to learn the non-nestmate odors is not necessarily limited to early and/or preimaginal life (i.e., the larval stage) by means of an imprinting process (Carlin et al., 1987; Fénéron \& Jaisson, 1995; Isingrini et al., 1985; Morel, 1982; Nowbahari \& Lenoir, 1989). Learning also occurs at the adult stage, and it may continue during the entire lifetime of a bee (Barrows, Bell, \& Michener, 1975) or of an ant, as shown here in C. niger. At this stage, the learning process consists of a continuous habituation to slight variations in the odor emanating from nestmates. As Vander Meer, Saliwanchik, and Lavine (1989) have demonstrated in Solenopsis invicta, and as several authors have since demonstrated in various other species (see review by Lenoir et al., 1999), the cuticular patterns of workers change continuously over time. Odor is a dynamic phenomenon. Adult workers are then able to adapt their behavior to the changing cuticular patterns by a process of odor learning. They can learn to recognize individual and/or colonial odors. In an artificially mixed colony (i.e., a colony comprising different ant species), ants acquire some of the hydrocarbon components characteristic of their allospecific nestmates, thus achieving a unified profile corresponding to a mixture of odors from both species (Errard, 1994; Errard, Hefetz, \& Jaisson, 2006). In such experimental conditions, ants from different colonies, which are usually very aggressive, can cohabit if they are grouped during their early life and remain nonaggressive throughout their adult life. Nevertheless, recognition learning and subsequent reductions in aggressive behavior are not always the result of similarities in hydrocarbon patterns. In naturally occurring parabiotic societies, ants are able to recognize nestmate and non-nestmate individuals of the associated species even though their cuticular profiles are different (Orivel, Errard, \& Dejean, 1997). In such a case, recognition can take place only through memorization or through familiarization with parabiotic individuals during the sensitive period. In $C$. niger, recognition also seems to be malleable in the adult stage by means of a sensory template encoding the labels (memory or familiarity). The hydrocarbon pattern modification that usually results from passive exchanges between individuals (Soroker et al., 1994) does not seem to have occurred in our experiments. Indeed, no trophallaxis or allogrooming was observed during the encounters.

Furthermore, the discrimination trial showed that ants subjected to repeated tests, in conspecific or heterospecific encounters, did not "forget" the colonial odor or template learned in early adult life. They distinguished nestmates from non-nestmates. This type of recognition necessarily implies long-term memory like that demonstrated in other ant species (see Errard, 1994). C. niger ants could also differentiate familiar from unfamiliar non-nestmates belonging to the same colony, even though they both presented some similarities in their odor profiles. Therefore, the retention of non-nestmate odors by $C$. niger adults might result from a narrowly specific individual odor learning, which would permit distinction between the slight differences in individual odors.

Our results show that ants can learn to recognize their colony odor early in life, but that when mature adults encounter non-nestmates repeatedly, they can learn to recognize non-nestmates individually as well. This process of learning as a consequence of confrontations seems to be context dependent and may constitute an individual strategy that increases fitness in ants.

\section{AUTHOR NOTE}

I am especially grateful to R. Fénéron, A. Lenoir, J. Todrank, and A. Hefetz for their helpful suggestions and comments. I thank J.-L. Durand for helping in statistics analysis and $\mathrm{J}$. Theau for his participation in performing this study, A. Pezon for English revision of a first version of this article, my friend C. Guignard for collecting ants in the field, and M.-C. Malherbe for rearing ants. This study was supported by the CNRS (France) and the MOST (Israel). Correspondence should be addressed to E. Nowbahari, Laboratoire d'Ethologie Expérimentale et Comparée, UMR CNRS 7153, Université Paris Nord, 99 Avenue J.-B. Clément, 93430 Villetaneuse, France (e-mail: elise.nowbahari@leec.univ-paris13.fr).

\section{REFERENCES}

Abramson, C. I. (1997). Where have I heard it all before? Some neglected issues of invertebrate learning. In G. Greenberg \& E. Tobach (Eds.), Comparative psychology of invertebrates: The field and laboratory study of insect behavior (pp. 55-78). New York: Garland.

Barrows, E. M., Bell, W. J., \& Michener, C. D. (1975). Individual odor differences and their social function in insects. Proceedings of the National Academy of Sciences, 7, 2824-2828.

Boulay, R., Katzav-Gozansky, T., Hefetz, A., \& Lenoir, A. (2004). Odour convergence and tolerance between nestmates through trophallaxis and grooming in the ant Camponotus fellah (Della Torre). Insectes Sociaux, 51, 55-61. 
Boulay, R., \& LENOIR, A. (2001). Social isolation of mature workers affects nestmate recognition in the ant Camponotus fellah. Behavioural Processes, 55, 67-73.

BREeD, M. D. (1998). Chemical cues in kin recognition: Criteria for identification, experimental approaches, and the honeybees as an example. In R. K. Vander Meer, M. D. Breed, K. E. Espelie, \& M. L. Wiston (Eds.), Pheromone communication in social insects: Ants, wasps, bees, and termites (pp. 57-78). Boulder, CO: Westview.

Breed, M. D., \& BennetT, B. (1987). Kin recognition in highly eusocial insects. In D. J. C. Fletcher \& C. D. Michener (Eds.), Kin recognition in animals (pp. 243-285). New York: Wiley.

Breed, M. D., \& Julian, G. E. (1992). Do simple rules apply in honeybee nestmate discrimination? Nature, 357, 685-686.

Breed, M. D., Smith, T. A., \& Torres, A. (1992). Role of guard honeybees (Hymenoptera: Apidae) in nestmate discrimination and replacement of removed guards. Annals of the Entomological Society of America, 85, 633-637.

Carlin, N. F., Halpern, R., Hölldobler, B., \& Schwartz, P. (1987). Early learning and the recognition of conspecific cocoons by carpenter ants (Camponotus spp.). Ethology, 75, 306-316.

CARlin, N. F., \& Johnston, A. B. (1984). Learned enemy specification in the defense recruitment system of an ant. Naturwissenschaften, 71, 156-157.

D'Ettorre, P., \& Heinze, J. (2005). Individual recognition in ant queens. Current Biology, 15, 2170-2174.

Dupuy, F., Sandoz, J. C., Giufra, M., \& Josens, R. (2006). Individual olfactory learning in Campontotus ants. Animal Behaviour, 72, 1081-1091

Erber, J., Masuhr, T. H., \& Menzel, R. (1980). Localization of shortterm memory in the brain of the bee, Apis mellifera. Physiological Entomology, 5, 343-358.

ERrard, C. (1994). Long-term memory involved in nestmate recognition in ants. Animal Behaviour, 48, 263-271.

Errard, C., Hefetz, A., \& Jaisson, P. (2006). Social discrimination tuning in ants: Template formation and chemical similarity. Behavioral Ecology \& Sociobiology, 59, 353-363.

FÉnÉron, R., \& JAISSON, P. (1995). Ontogeny of nestmate brood recognition in a primitive ant, Ectatomma tuberculatum Olivier (Ponerinae). Animal Behaviour, 50, 9-14.

GREENBERG, L. (1988). Kin recognition in the sweet bee, Lasiogloosum zephyrum. Behavior Genetics, 18, 425-437.

Heinze, J., Foitzik, S., Hippert, A., \& Hölldobler, B. (1996). Apparent dear-enemy phenomenon and environment-based recognition cues in the ant Leptothorax nylanderi. Ethology, 102, 510-522.

HowARD, R. W. (1993). Cuticular hydrocarbons and chemical communication. In D. W. Stanley-Samuelson \& D. R. Nelson (Eds.), Insect lipids: Chemistry, biochemistry, and biology (pp. 179-229). Lincoln: University of Nebraska Press.

IsINGRINI, M., Lenoir, A., \& JAISSON, P. (1985). Preimaginal learning as a basis of colony-brood recognition in the ant Cataglyphis cursor. Proceedings of the National Academy of Sciences, 82, 8545-8547.

KnAden, M., \& Wehner, R. (2003). Nest defense and conspecific enemy recognition in the desert ant Cataglyphis fortis. Journal of Insect Behavior, 16, 717-730.

Lahav, S., Soroker, V., Hefetz, A., \& Vander Meer, R. K. (1999). Direct behavioral evidence for hydrocarbons as ant recognition discriminators. Naturwissenschaften, 86, 246-249.

Langen, T. A., Tripet, F., \& Nonacs, P. (2000). The red and the black: Habituation and the dear-enemy phenomenon in two desert Pheidole ants. Behavioral Ecology \& Sociobiology, 48, 285-292.

Le Moli, F., \& Mori, A. (1985). The influence of the early experience of worker ants on enslavement. Animal Behaviour, 33, 1384-1386.

Lenoir, A., Cuisset, D., \& Hefetz, A. (2001). Effects of social isolation on hydrocarbon pattern and nestmate recognition in the ant Aphaenogaster senilis (Hymenoptera, Formicidae). Insectes Sociaux, 48, 101-109.

Lenoir, A., Fresneau, D., Errard, C., \& Hefetz, A. (1999). Individu- ality and colonial identity in ants: The emergence of the social representation concept. In C. Detrain, J. L. Deneubourg, \& J. M. Pasteels (Eds.), Information processing in social insects (pp. 219-223). Basel: Birkhäuser.

Manning, A., \& Dawkins, M. S. (1998). An introduction to animal behaviour (5th ed.). Cambridge: Cambridge University Press.

Morel, L. (1982). Mise en place des processus de régulation du comportement agressif et de la reconnaissance entre ouvrières d'une société de Camponotus vagus Scop. (Hymenoptera: Formicidae). In A. De Harom \& X. Espadaler (Eds.), La communication chez les sociétés d'insectes (pp. 127-136). Barcelona: Press Universitat Autònoma de Barcelona.

Nowbahari, E., Fénéron, R., \& Malherbe, M.-C. (1999). Effect of body size on aggression in the ant Cataglyphis niger (Hymenoptera; Formicidae). Aggressive Behavior, 25, 369-379.

Nowbahari, E., \& LenoIr, A. (1989). Age-related changes in aggression in ant Cataglyphis cursor (Hymenoptera, Formicidae): Influence on intercolonial relationships. Behavioural Processes, 18, 173-181.

Nowbahari, E., Lenoir, A., Clément, J.-L., Lange, C., Bagnères, A.-G., \& Joulie, C. (1990). Individual, geographical and experimental variation of cuticular hydrocarbons of the ant Cataglyphis cursor (Hymenoptera; Formicidae): Their use in nest and subspecies recognition. Biochemical Systematics \& Ecology, 18, 63-73.

Obin, M. S., \& VANDER MeER, R. K. (1988). Sources of nestmate recognition cues in the imported fire ant Solenopsis invicta Buran (Hymenoptera: Formicidae). Animal Behaviour, 36, 1361-1370.

Orivel, J., ERraRd, C., \& DEJEAN, A. (1997). Ant gardens: Interspecific recognition in parabiotic ant species. Behavioral Ecology \& Sociobiology, 40, 87-93.

Ozaki, M., Wada-Katsumata, A., Fujikawa, K., Iwasaki, M., YOKOHARI, F., SATOJI, Y., ET AL. (2005). Ant nestmate and non-nestmate discrimination by a chemosensory sensillium. Science, 309, 311-314.

Pfenning, D. W., Gamboa, G. J., Reeve, H. K., Shellman-Reeve, J., \& Ferguson, I. D. (1983). The mechanism of nestmate discrimination in social wasps (Polistes, Hymenoptera: Vespidae). Behavioral Ecology \& Sociobiology, 13, 299-305.

Soroker, V., Vienne, C., Hefetz, A., \& Nowbahari, E. (1994). The postpharyngeal gland as a "Gestalt" organ for nestmate recognition in the ant Cataglyphis niger. Naturwissenschaften, 81, 510-513.

StuART, R. J. (1987). Transient nestmate recognition cues contribute to a multicolonial population structure in the ant Leptothorax curvispinosus. Behavioral Ecology \& Sociobiology, 21, 229-235.

Temeles, E. J. (1994). The role of neighbors in territorial systems: When are they "dear enemies"? Animal Behaviour, 47, 339-350.

Todrank, J., \& Heth, G. (2003). Odor-genes covariance and genetic relatedness assessments: Rethinking odor-based "recognition" mechanisms in rodents. In P. Slater, J. Rosenblatt, C. Snowdon, \& T. Roper (Eds.), Advances in the study of behavior (Vol. 32, pp. 77-130). Amsterdam: Elsevier.

Vander Meer, R. K., Saliwanchik, D., \& Lavine, B. (1989). Temporal changes in colony cuticular hydrocarbon patterns of Solenopsis invicta: Implications for nestmate recognition. Journal of Chemical Ecology, 15, 2115-2125.

Velásquez, N., Gómez, M., González, J., \& VÁsquez, R. A. (2006) Nest-mate recognition and the effect of distance from the nest on the aggressive behaviour of Camponotus chilensis (Hymenoptera: Formicidae). Behaviour, 143, 811-824.

Wilson, E. O. (1975). Enemy specification in the alarm-recruitment system of an ant. Science, 190, 798-800.

Wyers, E. J., Peeke, H. V. S., \& Herz, M. J. (1973). Behavioral habituation in invertebrates. In H. V. S. Peeke \& M. J. Herz (Eds.), Habituation: Vol. I. Behavioral studies (pp. 1-57). New York: Academic Press.

(Manuscript received February 10, 2006; revision accepted for publication January 10, 2007.) 